\title{
The Antimetabolite ara-CTP Blocks Long-Term Memory of Conditioned Taste Aversion
}

\author{
Jianpeng Wang, ${ }^{1}$ Keqin Ren, ${ }^{1}$ Javier Pérez, ${ }^{1}$ Alcino J. Silva, ${ }^{2}$ and \\ Sandra Peña de Ortiz ${ }^{1,3}$
${ }^{1}$ Department of Biology, University of Puerto Rico, San Juan 00931-3360, Puerto Rico; ${ }^{2}$ Department of Neurobiology, University of California, Los Angeles, Los Angeles, California 90095-1761, USA

\begin{abstract}
We examined the hypothesis that processes related to DNA recombination and repair are involved in learning and memory. Rats received intracerebroventricular (icv) infusions of the antimetabolite 1-beta-D-arabinofuranosylcytosine triphosphate (ara-CTP) or its precursor cytosine arabinoside (ara-C) 30 min prior to conditioned taste aversion (CTA) training. Both ara-CTP and ara-C caused significant impairments in long-term memory (LTM) of CTA. Control experiments indicate that the effect of ara-CTP on CTA memory is related to interference with learning. Furthermore, as it was previously demonstrated for the protein synthesis inhibitor anisomycin, ara-CTP had no effect on CTA memory when it was injected $1 \mathrm{~h}$ after training. Importantly, although both ara-CTP and anisomycin significantly blocked LTM in the task, short-term memory (STM) measured $1 \mathrm{~h}$ after training was not affected by either of the drugs. Finally, ara-CTP had no effect on in vitro transcription, but it did effectively block nonhomologous DNA end joining (NHE)) activity of brain protein extracts. We suggest that DNA ligase-mediated DNA recombination and repair processes are necessary for the expression of LTM in the brain.
\end{abstract}

Long-term memory (LTM) is known to require the production of new proteins in the brain via the regulation of gene transcription and translation mechanisms (Goelet et al. 1986; Bailey et al. 1996; Yin and Tully 1996; Silva 2003). Additionally, several reports have postulated the idea that regulation of gene expression and function by DNA recombination mechanisms may also be involved in learning and memory processes (Dietrich and Been 2001; Peña de Ortiz and Arshavsky 2001). In support of this idea, the expression of the gene encoding terminal deoxynucleotidyl transferase, a template-independent DNA polymerase involved in Variable, Diversity, Joining (V(D)J) recombination, was shown to be modulated by behavioral training in neurons and to be required for the beneficial effects of enriched experience on learning (Peña de Ortiz et al. 2003).

Recent evidence suggests that DNA double strand breaks (DSBs) are introduced in the genome of neurons during the course of normal development, and that repair of such DSBs is essential for neuronal survival (Gao et al. 1998; Gu et al. 2000). Specifically, targeted mutation of genes encoding factors involved in NHEJ and V(D)J recombination, such as the X-ray complementation factor 4, DNA ligase IV, and Ku80, resulted in impaired neurogenesis in mice (Gao et al. 1998; Frank et al. 2000; Lee et al. 2000). Our previous studies showed that the mature rat brain retains the capacity for the repair of DSBs by DNA ligasedependent NHEJ (Ren and Peña de Ortiz 2002). ara-CTP and its inactive precursor, ara-C, are antimetabolites that have a plurality of effects on DNA metabolism. ara-CTP inhibits DNA ligase activity by blocking the formation of the adenylate complex essential for completion of the DNA joining reaction (Zittoun et al. 1991). In addition, ara-CTP is a competitive inhibitor of DNA polymerases $\alpha$ and $\beta$ and can be incorporated into DNA, resulting in the interruption of DNA synthesis and DNA repair processes (Ohno et al. 1988; Wang et al. 1990; Gandhi et al. 1997; Abdel-

\section{${ }^{3}$ Corresponding author.}

E-MAIL spena@upracd.upr.clu.edu; FAX (787) 764-3875.

Article and publication are at http://www.learnmem.org/cgi/doi/10.1101/ Im.63003.
Aziz et al. 2000; Han et al. 2000). Importantly, DNA polymerase $\beta$ is a known component of the base excision repair pathway (Idriss et al. 2002) and similarly to factors involved in NHEJ and $\mathrm{V}(\mathrm{D}) \mathrm{J}$ recombination, it is required for embryonic neurogenesis in mice (Gao et al. 1998; Sugo et al. 2000). Accordingly, rodents exposed prenatally to ara-C suffered from abnormal neuronal development resulting in impaired discrimination learning, hyperactivity, and aggression in the animals as adults (Adlard et al. 1975; Gray Jr. et al. 1986). Overall, processes that require the activities of DNA ligase and DNA polymerase, such as DNA replication, recombination, and repair are inhibited by ara-CTP. However, the use of ara-C, also known as cytarabine, as an antineoplastic agent stems mostly from its effects on DNA replication and cell division (Grant 1998; Esteva et al. 2000; Hamada et al. 2002). Interestingly, ara-C and other similarly acting antimetabolites have been reported to cause cognitive impairments (Giralt et al. 1992; Ferguson and Ahles 2003), suggesting that processes related to DNA metabolism might be important for higher brain functions. We report here that acute administration of ara-CTP into the brain of adult rats blocks LTM, but not short-term memory (STM), of conditioned taste aversion (CTA).

\section{RESULTS}

\section{ara-CTP Interferes With LTM of CTA}

As in previous studies (Ge et al. 2003), animals were subjected to a CTA protocol using a $0.1 \%$ dextrose solution as the conditioned stimulus (CS) and an intraperitoneal (ip) injection of lithium chloride ( $\mathrm{LiCl}$ ) as the unconditioned stimulus (US). We first examined the effects of ara-CTP, infused bilaterally into the cerebral ventricles $30 \mathrm{~min}$ prior to acquisition of CTA, on LTM tested at 24 and $72 \mathrm{~h}$ after training (Fig. 1A,B). Two-way ANOVA of the aversion index data $(n=10$ per group) showed that there were significant differences between treatments (treatment factor: $\left.F(1,36)=11.19,{ }^{* \star} P<0.005\right)$, but not across timepoints. Multiple comparisons analysis with the Bonferroni posttest identified specific significant differences at the 24 -h test timepoint $\left({ }^{*} P<0.05\right)$. Importantly, we found no difference in the levels of total liquid 
$\mathbf{A}$

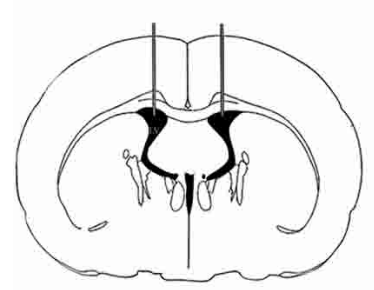

B

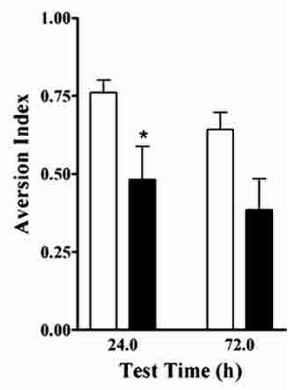

C



D

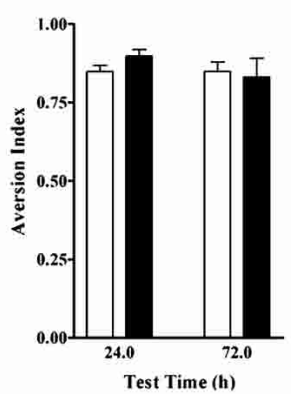

Figure 1 Effects of ara-CTP on LTM. (A) Schematic drawing of a rat brain section at plane $\mathrm{A} X \mathrm{pf}$ from the Paxinos and Watson rat brain atlas (1998), indicating the location of cannula implantations within the cerebral ventricles. $(B)$ The average \pm SEM values of aversion index for araCTP (black bars)-infused rats were significantly lower than those of the vehicle (white bars)-treated animals ${ }^{*} P<0.05$ at the 24 -h timepoint by Bonferroni posttesting). (C) The total volume of liquid ingestion for rats in the vehicle (white bars) and ara-CTP (black bars) groups. No significant differences were identified between the groups. $(D)$ Aversion indices at 24 and $72 \mathrm{~h}$ were similar between the vehicle (white bars) and ara-CTP (black bars) groups when animals were subjected to a second CTA experience in the absence of additional infusions.

consumption across treatments or timepoints tested (Fig. 1C), indicating that ara-CTP did not cause general toxicity to the animals. Thus, the difference in the mean values of aversion index between the two groups reflected differences in memory: Unlike ara-CTP-treated animals, vehicle-infused rats preferred plain water over the dextrose solution, indicating that they learned the CTA paradigm, whereas the ara-CTP-treated animals did not.

\section{ara-CTP-Treated Animals Retain the Capacity for New CTA Learning}

After the first training protocol, the animals were given extinction training and were then subjected to a new CTA experience, this time in the absence of additional drug infusions and using glycine as the new CS. We found no significant differences between the groups ( $\mathrm{n}=10$ per group), both of which could learn and remember the new experience as evidenced by aversion indices over 75\% (Fig. 1D). The results show that the ara-CTPtreated rats retained their ability to learn and remember a new CTA experience presented to them 1 wk after treatment. This result shows that the ara-CTP treatment did not cause irreversible toxic damage on the neural circuits involved in CTA learning and consolidation.

\section{The Effects of ara-CTP Are Related to CTA Learning} We next tested whether ara-CTP affected the establishment of the association between the CS and US. Thus, we subjected rats to mock CTA training, in which they were exposed to the CS after

receiving vehicle $(n=8)$ or ara-CTP $(n=10)$ infusions, but were then injected with saline rather than with the US. We then tested their preference for the CS over plain water at 4, 24, 72, and 120 h (Fig. 2A). As expected, both the vehicle- and ara-CTP-injected rats showed similarly low levels of CS aversion (at or below 0.5) in the mock training (MT) protocol $(P<0.05$ for time and treatment factors in two-way ANOVA). Additional animals were subjected to a CTA posttraining (PT) drug infusion protocol, in which they received ara-CTP $(n=7)$ or vehicle $(n=8)$ infusions 1 $\mathrm{h}$ after training. As shown in Figure 2B, both groups showed similarly high levels of aversion (index at 0.7 or above) to the CS $(P<0.05$ for time and treatment factors in two-way ANOVA) in the PT drug infusion protocol. Thus, ara-CTP did not affect the response to the CS if presented in the absence of the US (Fig. 2A) or if the drug was given $1 \mathrm{~h}$ after presentation of the US (Fig. 2B). The results indicate that in order to block CTA consolidation, ara-CTP must be present at the time of conditioning.

\section{ara-C Also Blocks LTM}

ara-CTP is the active metabolite of the antineoplastic drug ara-C, which is used as a chemotherapeutic agent in cancer (Grant 1998; Esteva et al. 2000; Hamada et al. 2002). Because ara-C is frequently used as an ara-CTP precursor agent that is converted into its active form intracellularly (Grant 1998), we decided to test whether ara-C could also act as a blocker of LTM in CTA.
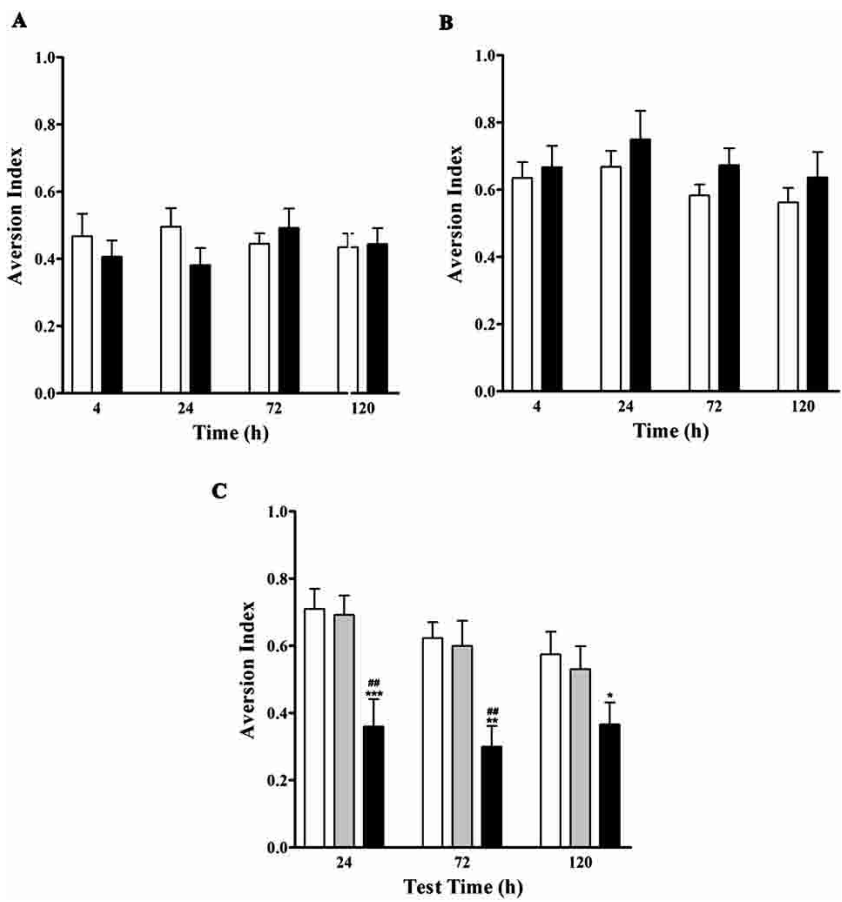

Figure 2 The effects of ara-CTP are related to CTA learning. ( $A$ ) The aversion indices of rats infused with vehicle (white bar) or ara-CTP (black bar) that were exposed to the CS, but not to the US as part of the MT protocol. Animals in both groups showed equally low aversive responses to the CS. (B) Animals in the PT protocol were injected with vehicle (white bars) or ara-CTP (black bars) $1 \mathrm{~h}$ after conditioning. Both groups displayed equally high aversive responses to the CS. (C) The mean aversion responses of animals receiving $1 \mathrm{mM}$ ara-C (black bars) were significantly lower than the responses of animals receiving vehicle (white bars) or 0.01 $\mathrm{mM}$ ara-C (gray bars) over the time period of 24 to $120 \mathrm{~h}$ after training (one-way ANOVA, ${ }^{* * *} P<0.001$ ). Multiple comparisons posttesting identified specific differences between ara- $C(1 \mathrm{mM})$ vs. ara-C $(0.01 \mathrm{mM})$ or between ara-C $(1 \mathrm{mM})$ vs. vehicle at $24\left({ }^{\# \#} P<0.01\right.$ and ${ }^{* * *} P<0.001$, respectively), $72\left({ }^{\# \star * *} P<0.01\right.$, each comparison), and $120 \mathrm{~h}\left({ }^{\star} P<0.05\right.$, vehicle only). 
Animals received an icv infusion of ara-C $(0.01 \mathrm{mM}$ or $1 \mathrm{mM})$ or vehicle $30 \mathrm{~min}$ prior to exposure to the CS and were tested at 24, 72 , and $120 \mathrm{~h}$ after presentation of the US. As shown in Figure 2C, a significant difference was identified among all the groups and timepoints tested (one-way ANOVA, $\mathrm{F}(8,125)=6.863$ ), ${ }^{* \star *} P<0.001$ ). Multiple comparisons testing showed that $1 \mathrm{mM}$ ara-C caused a significant impairment in LTM compared to the vehicle when memory was tested at $24\left({ }^{* * *} P<0.001\right), 72$ $\left({ }^{* *} P<0.01\right)$, and $120 \mathrm{~h}$ after training $\left({ }^{*} P<0.05\right)$. Rats treated with $1 \mathrm{mM}$ ara-C showed significantly lower aversion to the CS than rats treated with $0.01 \mathrm{mM}$ ara-C, when tested at 24 and $72 \mathrm{~h}$ (\#\# $P<0.01$ each comparison). No significant differences were identified between vehicle and the $0.01 \mathrm{mM}$ ara-C dose at any of the timepoints.

\section{Blockade of DNA Recombination/Repair Processes Does Not Affect STM for CTA}

LTM is known to require protein synthesis and gene transcription, whereas STM does not (Goelet et al. 1986; Bailey et al. 1996; Yin and Tully 1996; Silva 2003). Specifically, CTA training with oral administration of the CS elicits protein synthesis-independent STM and protein synthesis-dependent LTM (Houpt and Berlin 1999). Our next experiments were aimed at testing the hypothesis that blockade of DNA recombination/repair processes also impairs LTM, but not STM. We trained additional animals following ara-CTP or vehicle icv infusions ( $\mathrm{n}=10$ per group) and tested them at 1, 4, 24, 72, and $120 \mathrm{~h}$ after conditioning (Fig. 3A). Two-way ANOVA detected significant overall differences in CTA memory between the groups across time and treatments (treatment factor: $F(1,90)=33.74,{ }^{* *} P<0.0001$; time factor: $F(4$,

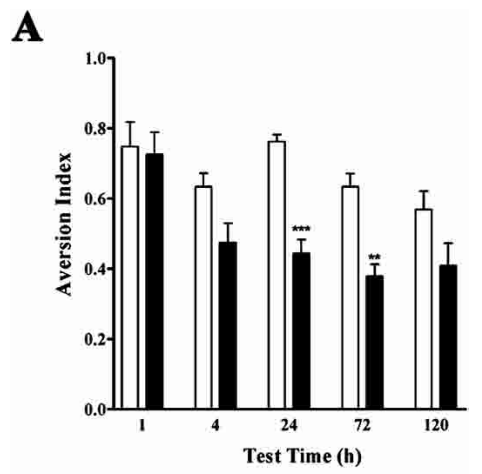

B

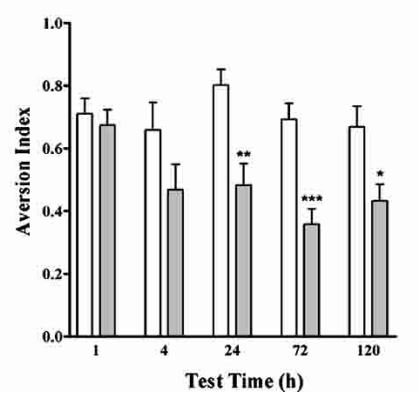

Figure 3 ara-CTP blocks LTM, but not STM. (A) The aversion index was significantly lower in ara-CTP (black bars) compared to vehicle (white bars) -infused animals tested at the 24- $\left({ }^{* * *} p<0.001\right)$ and $72-h$ $\left({ }^{* *} P<0.01\right)$ timepoints, but not at 1,4 , or $120 \mathrm{~h}$. (B) Anisomycin (gray bars) -treated animals showed significantly lower aversion to the CS than controls (white bars) at the 24- $\left.{ }^{* *} P<0.01\right), 72-\left({ }^{* *} P<0.001\right)$, and $120-\mathrm{h}\left({ }^{*} P<0.05\right)$ timepoints, but not at 1 or $4 \mathrm{~h}$ after conditioning. $\left.90)=7.947,{ }^{* * *} P<0.0001\right)$. The analysis also identified a significant interaction between the treatment and time factors $(F(4$, $90)=2.539, P<0.05)$, indicating that the effect of ara-CTP varied across timepoints. In fact, posttesting analysis showed that the effects of ara-CTP reached significance at the $24-\left({ }^{\star * *} P<0.001\right)$ and 72 -h $\left({ }^{*} P<0.01\right)$ timepoints, but not at 1,4 , or $120 \mathrm{~h}$. We next used the protein synthesis inhibitor anisomycin (ManahanVaughan et al. 2000) to compare the effects of inhibition of translation with those of ara-CTP and ara-C. Animals received icv infusions of vehicle or anisomycin $30 \mathrm{~min}$ prior to training ( $\mathrm{n}=11$ per group). As expected, the effects of anisomycin (Fig. 3B) were similar to those observed for ara-CTP and ara-C (Figs. 3A and 2C, respectively). Two-way ANOVA indicated that anisomycin exerted a significant effect on the development of aversion to the CS (treatment factor: $F(1,96)=33.46, P<0.0001$; time factor: $F(4,96)=2.6 .49, P<0.05)$, although no significant treatment/ time interaction was observed. Multiple comparisons posttesting revealed specific significant differences between the treatments at the $24-\left({ }^{\star \star} P<0.01\right), 72-\left({ }^{* *} P<0.001\right)$, and $120-\mathrm{h}\left({ }^{*} P<0.05\right)$ timepoints. As observed for ara-CTP (Fig. 1B), anisomycin blocked LTM of CTA, but had no effect on short-term behavioral plasticity detected at 1 or $4 \mathrm{~h}$ after conditioning. Together, the results suggest that the effects of ara-CTP on LTM might be due, as for anisomycin, to impairment of learning-induced changes in gene expression and function.

\section{ara-CTP Blocks NHE] Activity, But Does Not Affect Transcription}

We next tested the biochemical effects of ara-CTP on DNA recombination and repair processes. We tested the effects of the drug on NHEJ activity in protein extracts prepared from the rat cerebrum $(n=3)$. As shown in Figure $4 A$, ara-CTP reduced the generation of dimeric and multimeric recombinant NHEJ products by brain protein extracts in a dose-dependent fashion. Doses between 1 and $10 \mathrm{mM}$ ara-CTP caused an increasingly stronger blockade of NHEJ activity assessed by significant reductions in multimeric (1-10 $\mathrm{mM})$ and dimeric $(7.5-10 \mathrm{mM})$ products. In contrast, ara-C (1-10 $\mathrm{mM})$ had no effect on NHEJ activity measured in vitro. As shown in Figure 4B, one-way ANOVA of the normalized NHEJ products confirmed the significant effect of ara-CTP on brain NHEJ activity $(F(5,17)=80.77, P<0.0001)$. Multiple comparisons of the different ara-CTP doses using a Newman-Keuls analysis showed specific significant effects of ara-CTP on NHEJ activity at $1 \mathrm{mM}(P<0.05)$ compared to the vehicle control. Higher ara-CTP concentrations $(2.5,5.0,7.5$, and 10 $\mathrm{mM})$ had more dramatic effects on NHEJ activity $(P<0.001$ each comparison). Finally, we decided to rule out the possibility that the effects of ara-CTP on CTA consolidation were due to effects on transcription rather than or in addition to effects on DNA recombination/repair mechanisms. For this aim, we tested the effects of various doses of ara-CTP on in vitro transcription. The results shown in Figure 4C demonstrate that ara-CTP does not affect transcription activity at doses lower than or equal to $1 \mathrm{mM}$. The mean optical density of the transcriptional products generated in the presence of each ara-CTP concentration is shown in Figure $4 \mathrm{D}(\mathrm{n}=5)$. Similar results have been obtained with ara-C in vivo (Casola et al. 1968).

\section{DISCUSSION}

Regulation of gene expression and function is known to be essential for LTM (Goelet et al. 1986; Bailey et al. 1996; Yin and Tully 1996; Peña de Ortiz and Arshavsky 2001; Silva 2003). The results presented here indicate that both ara-CTP and ara-C are capable of blocking LTM formation in CTA, a special form of classical conditioning. Here, ara-CTP and ara-C were adminis- 
$\mathbf{A}$
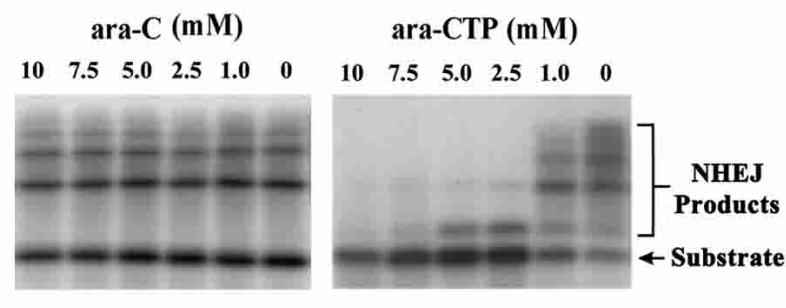

$\mathbf{C}$

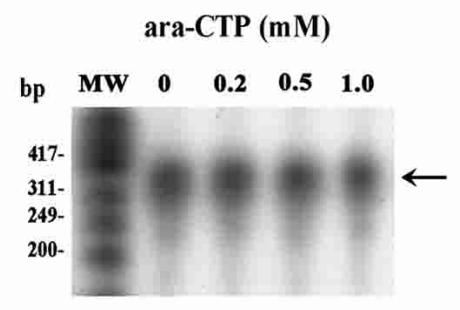

B

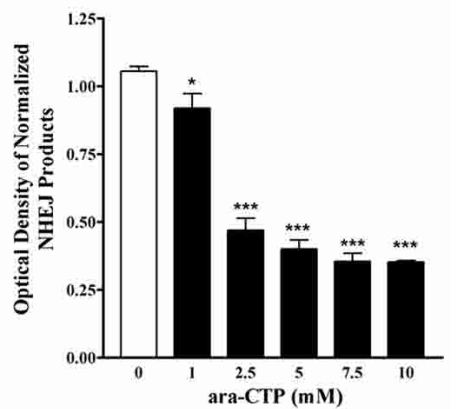

D

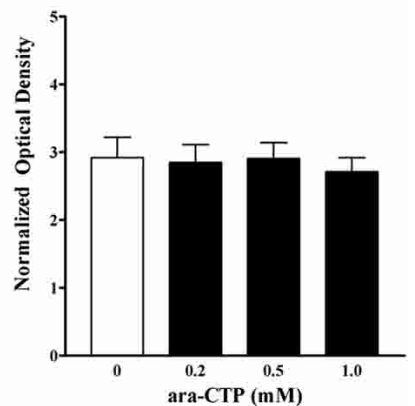

Figure 4 Effects of ara-CTP on NHEJ and in vitro transcription. ( $A$ ) ara-CTP (right panel) blocked the production of recombinant NHEJ products at 1 to $10 \mathrm{mM}$ concentrations, whereas ara-C (left panel) had no effect on the reaction at the same concentrations. (B) Densitometric and statistical analysis of mean OD values ( \pm SEM) corresponding to NHEJ products in the presence of varying concentrations of ara-CTP. One-way ANOVA showed that ara-CTP significantly reduced the production of recombinant products at $1,2.5,5,7$, and 10 mM compared to vehicle ( ${ }^{\star \star *} P<0.001$ each comparison except for the $1 \mathrm{mM}$ dose, $\left.{ }^{*} P<0.05\right)$. (C) ara-CTP had no effects on in vitro transcription at the same concentrations that blocked NHEJ. (D) Densitometric analysis showing no significant effect by any of the concentrations of ara-CTP tested on in vitro transcription.

tered directly into the cerebral ventricles to avoid the possibility of systemic toxicity, an eventuality that would affect the interpretation of our results. Importantly, the fact that rats infused with vehicle or ara-CTP showed similar levels of total liquid consumption argues against the idea that the effects of the drug on CTA memory response are related to general systemic impairment. Our next goal was to assess whether the animals previously treated with ara-CTP could learn a new CTA experience in the absence of the drug. We decided to extinguish the aversive memory toward dextrose in all animals before subjecting the animals to a new CTA experience with a new CS, in order to avoid the possibility of enhanced neophobia. Animals are naturally phobic of novel flavors (Bond et al. 1989), a phenomenon that might be potentiated just after experiencing CTA and that has been referred to as conditioning-enhanced neophobia (Best and Batson 1977; Franchina and Dyer 1985). We also avoided the use of dextrose as the CS in the second CTA experience, to ensure that our results were not confounded by the fact that the animals had already experienced drinking dextrose and no longer recognized it as a new flavor. Using glycine as the CS in the second CTA would prevent the potential interference of previous experience in the new learning. A similar protocol was reported previously (Naor and Dudai 1996).

We observed that the same animals in which ara-CTP blocked LTM of CTA were able to acquire and remember, as did vehicle controls, a second conditioning experience in which they were presented with a new CS in the absence of additional drug treatment (Fig. 2A). These results suggest that ara-CTP did not cause major cellular damage in the brain and that the neural pathways required for CTA learning and memory remained intact and available for acquisition of a new conditioning experience.

Further evidence supporting the specificity of the effects of
ara-CTP is given by the finding that animals treated with the drug prior to presentation of a novel flavor, in the absence of a subsequent aversive experience, showed future preference toward that flavor over plain water, as did controls (Fig. 2B, MT groups). Moreover, injecting ara-CTP $1 \mathrm{~h}$ after training had no effect on consolidation of CTA (Fig. 2B, PT groups), showing that the drug had to be present in the brain at the time of conditioning in order to have an effect on LTM. These results agree with previous findings with anisomycin in learning (Grecksch and Matthies 1980; Bourtchouladze et al. 1998). Because administration of anisomycin immediately after training blocks LTM in several learning tasks (Grecksch and Matthies 1980; Bourtchouladze et al. 1998; Naghdi et al. 2003), it is possible that similar results could be found with ara-CTP in CTA. Overall, these data suggest that the processes inhibited by ara-CTP need to be active at the time of conditioning in order to generate associative LTM. Moreover, such processes might be activated as a result of associative learning in parallel to the known activation of transcription factors, such as the cAMP Response Element Binding protein (Lamprecht et al. 1997; Josselyn et al. 2002).

The transition from STM to LTM in CTA depends on the activation of gene expression processes, including protein synthesis (Bailey et al. 1999). Previous studies have shown that inhibition of protein synthesis does not interfere with the expression of CTA memory measured $1 \mathrm{~h}$ after conditioning, but significantly affects memory measured at later timepoints (Houpt and Berlin 1999). Our studies with anisomycin replicated this finding. In addition, we show that ara-CTP, as well as anisomycin (Fig. 3), blocks LTM of CTA, while not affecting STM measured 1 $\mathrm{h}$ after conditioning. In particular, for both ara-CTP and anisomycin, lower mean values of aversion to the CS were observed at 4, 24, 72, and $120 \mathrm{~h}$, compared to controls. However, the 4-h timepoint did not reach significance in post-hoc tests for either 
of the drugs, possibly because it represents an intermediate stage in the transition from STM to LTM. On the other hand, although both treatments showed similar effects at $120 \mathrm{~h}$ (see also the effects of ara-C, Fig. 2C), only anisomycin reached significance in a post-hoc analysis of this timepoint. As discussed below, by blocking protein synthesis, anisomycin is probably interfering with the expression of a larger set of genes than ara-CTP, which would specifically affect LTM-related genes regulated by recombination/repair processes. Thus, a milder effect by ara-CTP at 120-h memory may reflect the fact that DNA recombination/ repair processes regulate only a subset of the genes regulated by protein synthesis. Finally, as in previous studies showing that blocking protein synthesis $1 \mathrm{~h}$ after fear conditioning in mice does not interfere with LTM (Bourtchouladze et al. 1998; Igaz et al. 2002), ara-CTP given $1 \mathrm{~h}$ after training also had no effect on CTA consolidation (Fig. 2B). Together, these findings strengthen the idea that processes related to DNA recombination and repair may be used as mechanisms of genomic regulation that operate upstream of protein synthesis and that eventually result in longterm changes in gene function, which in turn may help stabilize synaptic connections, enhance neurotransmission, or potentiate intracellular signaling, as previously proposed by Peña de Ortiz and Arshavsky (2001).

Experience-dependent activation of neurogenesis is known to require long-term behavioral stimulation (Kempermann et al. 1998; Gould et al. 1999; Nilsson et al. 1999; van Praag et al. 2000; Shors et al. 2001). Thus, it is unlikely that the rapid effects of ara-CTP on consolidation of a single-trial conditioning task, as the one used here, are the result of blocking neurogenesis. Rather, it is possible that the effects of ara-CTP on LTM are related to its effects on DNA ligase and/or DNA polymerase-mediated illegitimate recombination and repair processes, such as NHEJ. In support of this notion, our results show that ara-CTP is capable of blocking NHEJ activity measured in protein extracts prepared from the rat brain (Fig. 4A,B). Repair of DSBs by NHEJ requires the activities of DNA polymerase, to "fill in" any protruding ends, and DNA ligase, for the final joining step (Shivji et al. 1995). We therefore propose that the effect of ara-CTP on NHEJ is due to its known effects on these enzymes, in particular DNA ligase. Although ara-C, the inactive precursor of ara-CTP, had no effect on NHEJ activity in vitro, the drug did impair LTM in vivo. The results suggest that ara-C must be converted intracellularly into ara-CTP before it can impair LTM by blocking DNA recombination and repair processes.

Finally, earlier findings showed that ara-C does not affect transcription in the goldfish brain (Casola et al. 1968). Accordingly, we found that ara-CTP had no effect on mammalian transcription measured in vitro (Fig. 4C,D). Based on these results and on the in vivo studies on the goldfish central nervous system, it is likely that ara-CTP and its precursor ara-C have no effect on transcription in the mammalian brain. DNA repair mechanisms that utilize DNA synthesis and joining enzymes are tightly associated with DNA recombination processes, such as $\mathrm{V}(\mathrm{D}) \mathrm{J}$, that involve cutting, repair, and rejoining (or ligation) mechanisms (Gellert 2002). Importantly, studies have shown that molecules related to signaling of T-cell receptors, which are subject to $\mathrm{V}(\mathrm{D}) \mathrm{J}$ recombination in immune cells, play significant roles in brain plasticity (Huh et al. 2000; Boulanger et al. 2001). Indeed, the idea that the storage of memories permanently in the brain could involve changes at the level of DNA has been previously proposed (Crick 1984; Peña de Ortiz and Arshavsky 2001). The results presented here indicating that disruption of DNA recombination and repair processes in the brain blocks LTM without affecting STM represent an important new insight that opens the door to the identification of the genes and cellular processes related to genome rearrangement and stability in memory formation.

\section{MATERIALS AND METHODS}

\section{Animals}

Male Long Evans rats (Harlan Sprague Dawley) weighing 275-325 $\mathrm{g}$ at the time of surgery were used. They were individually caged at $22 \pm 2^{\circ} \mathrm{C}$ in a 12 -h light/12-h dark cycle, with food and water ad libitum, except during behavioral tests.

\section{Surgery}

Surgical procedures were done $4 \mathrm{~d}$ after the arrival of the animals at our animal facility. Rats were anesthetized with $2.5 \%$ sodium pentobarbital at a dose of $50 \mathrm{mg} / \mathrm{kg}$, ip. The head was positioned in a stereotaxic frame, and a midline sagittal incision was made in the scalp. Two holes were drilled in the skull, and stainless steel guide cannulas (26 ga.) were lowered to a position just above the cerebral ventricles (Fig. 1A). The stereotaxic coordinates with respect to bregma were $0.8 \mathrm{~mm}$ caudal, $1.4 \mathrm{~mm}$ lateral (Paxinos and Watson 1998). Cannulas were lowered $2.8 \mathrm{~mm}$ below the surface of the skull and were then fixed with small screws and dental cement. A stainless steel wire stylet (33 ga.) was inserted into each guide cannula to prevent leakage of the cerebrospinal fluid, as well as to prevent obstruction. After surgery, animals were allowed to recover for 3-5 d before behavioral experiments were begun.

\section{Behavioral Training and Drug Infusions}

The CTA training was done as previously described by us (Ge et al. 2003). To assess the effectiveness of the infusion pump system and to get the animals used to receiving icv infusions, we subjected each animal to bilateral infusions ( 5 min at $0.25 \mu \mathrm{L} / \mathrm{min}$ ) of vehicle $(50 \%$ dymethylsulfoxide $+50 \%$ of $0.9 \%$ saline or $0.9 \%$ saline for the ara-CTP/ara-C and anisomycin studies, respectively) on the day prior to conditioning. Infusions were done by inserting 33-gauge stainless steel internal cannulas into the guide cannulas so that they extended $1 \mathrm{~mm}$ beyond the tip of the guide into the lateral ventricles. The next day, animals were randomly separated into two groups that received ara-CTP (Sigma) at $1 \mathrm{mM}$ working concentration, ara-C (Sigma) at either 0.01 or $1 \mathrm{mM}$ working concentrations, $240 \mu \mathrm{g}$ anisomycin (Sigma), prepared as described (Manahan-Vaughan et al. 2000), or vehicle infusions (see above) $30 \mathrm{~min}$ prior to training. Animals were then presented with the CS (a 0.1\% dextrose solution) using the bottle presentation method (Ge et al. 2003), instead of plain water as in previous days and allowed to drink for $10 \mathrm{~min}$. Forty minutes later, the animals received an ip injection of $\mathrm{LiCl}(100 \mathrm{mg} / \mathrm{kg})$, the US. For the MT protocol, animals were injected with $0.9 \%$ saline, instead of the US, 40 min after presentation of the CS. In the PT infusions, animals received ara-CTP or vehicle $1 \mathrm{~h}$ after presentation of the US. Memory was tested at 1, 4, 24, 72, or 120 $\mathrm{h}$ by presenting the animals with plain water and dextrose solution and allowing them to drink for $10 \mathrm{~min}$. Liquid consumption was measured by weighing the drinking bottles before and after training. Associative learning and memory were assessed by the development of aversion to the CS, measured as an Aversion Index calculated as follows: water intake/(water intake + dextrose intake). For extinction, animals were presented with the CS in the absence of the US for five consecutive days.

\section{In Vitro Transcription}

The impact of ara-CTP on transcription was assayed in a HeLa nuclear extract in vitro transcription system under conditions recommended by the manufacturer (Promega). Briefly, vehicle or ara-CTP was incubated in a $25-\mu \mathrm{L}$ reaction containing $50 \mathrm{mM}$ $\mathrm{MgCl}_{2}, 0.4 \mathrm{mM}$ each ATP, CTP, and UTP, $16 \mu \mathrm{M}$ GTP, $100 \mathrm{ng}$ linearized cytomegalovirus DNA, $8 \mu \mathrm{L}$ Hela Nuclear Extract, $3 \mu \mathrm{L}$ HeLa Nuclear Extract $1 \mathrm{X}$ Transcription Buffer, and $10 \mu \mathrm{Ci}\left[\alpha-{ }^{32} \mathrm{P}\right]$ rGTP at $30^{\circ} \mathrm{C}$ for $60 \mathrm{~min}$. Termination of the reaction was performed by addition of $175 \mu \mathrm{L}$ of Stop Solution. The products were extracted with $200 \mu \mathrm{L}$ of phenol/chloroform and then precipitated with $500 \mu \mathrm{L}$ of ethanol. The pellets were resuspended in 10 $\mu \mathrm{L}$ of nuclease-free water. Size markers were prepared with the 
DNA 5' End-Labeling System (Promega). Briefly, $1 \mu \mathrm{g}$ of digested $\varphi$ X174 Hinf I DNA, $5 \mu \mathrm{L} 10 \mathrm{X}$ reaction buffer, $150 \mu \mathrm{Ci}\left[\gamma_{-}{ }^{32} \mathrm{P}\right] \mathrm{ATP}$, and 10 Units $\mathrm{T} 4$ Polynucleotide Kinase were incubated at $37^{\circ} \mathrm{C}$ for $10 \mathrm{~min}$. The transcription products and labeled size marker were heated at $90^{\circ} \mathrm{C}$ for $10 \mathrm{~min}$ and analyzed on a denaturing gel containing $6 \%$ acrylamide, $7 \mathrm{M}$ urea, and $0.5 \mathrm{X}$ Tris-Borate-EDTA buffer. Reaction products were visualized by x-ray film autoradiography. Films were scanned with a calibrated Personal Densitometer (Molecular Dynamics), and optical density (OD) measurements were taken using the ImageQuant software package (Molecular Dynamics).

\section{NHE] Assays}

NHEJ assays were performed as described (Ren and Peña de Ortiz 2002). A standard in vitro end-joining reaction $(50 \mu \mathrm{L})$ contained $20 \mathrm{ng}$ linearized DNA substrate, $50 \mu \mathrm{g}$ brain protein extract, 1 $\mathrm{mM}$ ATP, and $10 \mu \mathrm{g}$ bovine serum albumin in NHEJ reaction buffer. ara-CTP was added to the extracts just prior to the addition of DNA substrates. Reactions were incubated at room temperature $\left(21^{\circ} \mathrm{C}\right)$ for $1 \mathrm{~h}$ and stopped by heating at $70^{\circ} \mathrm{C}$ for 10 min. The DNA end-joining products were separated by electrophoresis in a $1 \%$ agarose gel at $100 \mathrm{~V}$ for $120 \mathrm{~min}$ and then analyzed by Southern blotting. The probe used was the linearized plasmid pBluescript SK, obtained by EcoRI digestion, and labeled with $\left[\alpha-{ }^{32} \mathrm{P}\right]$ dCTP using the RediPrimeTM II Kit (AmershamPharmacia Biotech). The labeled DNA probe was then purified with a Nick Column (Amersham-Pharmacia Biotech) and subsequently used to hybridize the reacted DNAs. Reaction products were visualized by $\mathrm{x}$-ray film autoradiography and scanned as described above. ODs of NHEJ products were normalized using the following formulas: for NHEJ analysis $=(\mathrm{OD}$ of all NHEJ products $) \div($ OD of NHEJ products + OD of substrate DNA).

\section{Statistical Analysis}

Prism 3.0 (GraphPad Software) was used for one-way or two-way analysis of variance (ANOVA) of the behavioral and biochemical data. Newman-Keuls and Bonferroni multiple comparisons tests were used to assess the differences in mean and standard error (SEM) between particular group pairs within data analyzed with one-way or two-way ANOVA, respectively.

\section{ACKNOWLEDGMENTS}

We would like to thank Drs. Gregory J. Quirk and Yuri Arshavsky for helpful comments on this manuscript. We also thank Giselle Flores for technical assistance with surgeries and behavioral studies. This work was supported by NIH (S.P.O. and A.J.S. SNRP-NIH grant U54 NS39405).

The publication costs of this article were defrayed in part by payment of page charges. This article must therefore be hereby marked "advertisement" in accordance with 18 USC section 1734 solely to indicate this fact.

\section{REFERENCES}

Abdel-Aziz, W., Jiang, H.Y., Hickey, R.J., and Malkas, L.H. 2000. Ara-C affects formation of cancer cell DNA synthesome replication intermediates. Cancer Chemother. Pharmacol. 45: 312-319.

Adlard, B.P., Dobbing, J., and Sands, J. 1975. A comparison of the effects of cytosine arabinoside and adenine arabinoside on some aspects of brain growth and development in the rat. Br. J. Pharmacol. 54: $33-39$.

Bailey, C.H., Bartsch, D., and Kandel, E.R. 1996. Toward a molecular definition of long-term memory storage. Proc. Natl. Acad. Sci. 93: $13445-13452$.

Bailey, D.J., Kim, J.J., Sun, W., Thompson, R.F., and Helmstetter, F.J. 1999. Acquisition of fear conditioning in rats requires the synthesis of mRNA in the amygdala. Behav. Neurosci. 113: 276-282.

Best, M.R. and Batson, J.D. 1977. Enhancing the expression of flavor neophobia: Some effects of the ingestion-illness contingency. J. Exp. Psychol. Anim. Behav. Process. 3: 132-143.

Bond, N.W., Everitt, A.V., and Walton, J. 1989. Effects of dietary restriction on radial-arm maze performance and flavor memory in aged rats. Neurobiol. Aging 10: 27-30.

Boulanger, L.M., Huh, G.S., and Shatz, C.J. 2001. Neuronal plasticity and cellular immunity: Shared molecular mechanisms. Curr. Opin. Neurobiol. 11: 568-578.

Bourtchouladze, R., Abel, T., Berman, N., Gordon, R., Lapidus, K., and Kandel, E.R. 1998. Different training procedures recruit either one or two critical periods for contextual memory consolidation, each of which requires protein synthesis and PKA. Learn. Mem. 5: 365-374.

Casola, L., Lim, R., Davis, R.E., and Agranoff, B.W. 1968. Behavioral and biochemical effects of intracranial injection of cytosine arabinoside in goldfish. Proc. Natl. Acad. Sci. 60: 1389-1395.

Crick, F. 1984. Memory and molecular turnover. Nature 312: 101.

Dietrich, A. and Been, W. 2001. Memory and DNA. J. Theor. Biol. 208: $145-149$.

Esteva, F.J., Soh, L.T., Holmes, F.A., Plunkett, W., Meyers, C.A., Forman, A.D., and Hortobagyi, G.N. 2000. Phase II trial and pharmacokinetic evaluation of cytosine arabinoside for leptomeningeal metastases from breast cancer. Cancer Chemother. Pharmacol. 46: 382-386.

Ferguson, R.J. and Ahles, T.A. 2003. Low neuropsychologic performance among adult cancer survivors treated with chemotherapy. Curr. Neurol. Neurosci. Rep. 3: 215-222.

Franchina, J.J. and Dyer, A.B. 1985. Aversion conditioning and enhanced neophobia: Role of test stimuli. Behav. Neural. Biol. 44: $122-131$.

Frank, K.M., Sharpless, N.E., Gao, Y., Sekiguchi, J.M., Ferguson, D.O., Zhu, C., Manis, J.P., Horner, J., DePinho, R., and Alt, F.W. 2000. DNA ligase IV deficiency in mice leads to defective neurogenesis and embryonic lethality via the p53 pathway. Mol. Cell. 5: 993-1002.

Gandhi, V., Huang, P., Chapman, A.J., Chen, F., and Plunkett, W. 1997. Incorporation of fludarabine and 1- $\beta$-D-arabinofuranosylcytosine 5 '-triphosphates by DNA polymerase $\alpha$ : Affinity, interaction, and consequences. Clin. Cancer Res. 3: 1347-1355.

Gao, Y., Sun, Y., Frank, K.M., Dikkes, P., Fujiwara, Y., Seidl, K.J., Sekiguchi, J.M., Rathbun, G.A., Swat, W., Wang, J., et al. 1998. A critical role for DNA end-joining proteins in both lymphogenesis and neurogenesis. Cell 95: 891-902.

Ge, H., Chiesa, R., and Peña de Ortiz, S. 2003. HZF-3 expression in the amygdala after establishment of conditioned taste aversion. Neuroscience 120: $1-4$.

Gellert, M. 2002. V(D)J recombination: RAG proteins, repair factors, and regulation. Annu. Rev. Biochem. 71: 101-132.

Giralt, J., Ortega, J.J., Olive, T., Verges, R., Forio, I., and Salvador, L. 1992. Long-term neuropsychologic sequelae of childhood leukemia: Comparison of two CNS prophylactic regimens. Int. J. Radiat. Oncol. Biol. Phys. 24: 49-53.

Goelet, P., Castellucci, V.F., Schacher, S., and Kandel, E.R. 1986. The long and the short of long-term memory-A molecular framework. Nature 322: 419-422.

Gould, E., Beylin, A., Tanapat, P., Reeves, A., and Shors, T.J. 1999. Learning enhances adult neurogenesis in the hippocampal formation. Nat. Neurosci. 2: 260-265.

Grant, S. 1998. Ara-C: Cellular and molecular pharmacology. Adv. Cancer Res. 72: 197-233.

Gray Jr., L.E., Kavlok, R.J., Ostby, J., Ferrel, J., Rogers, J., and Gray, K. 1986. An evaluation of figure-eight maze activity and general behavioral development following prenatal exposure to forty chemicals: Effects of cytosine arabinoside, dinocap, nitrofen, and vitamin A. Neurotoxicology 7: 449-462.

Grecksch, G. and Matthies, H. 1980. Two sensitive periods for the amnesic effect of anisomycin. Pharmacol. Biochem. Behav. 12: 663-665.

Gu, Y., Sekiguchi, J., Gao, Y., Dikkes, P., Frank, K., Ferguson, D., Hasty, P., Chun, J., and Alt, F.W. 2000. Defective embryonic neurogenesis in Ku-deficient but not DNA-dependent protein kinase catalytic subunit-deficient mice. Proc. Natl. Acad. Sci. 97: 2668-2673.

Hamada, A., Kawaguchi, T., and Nakano, M. 2002. Clinical pharmacokinetics of cytarabine formulations. Clin. Pharmacokinet. 41: $705-718$.

Han, S., Hickey, R.J., Tom, T.D., Wills, P.W., Syvaoja, J.E., and Malkas, L.H. 2000. Differential inhibition of the human cell DNA replication complex-associated DNA polymerases by the antimetabolite $1-\beta-D$-arabinofuranosylcytosine triphosphate (ara-CTP). Biochem. Pharmacol. 60: 403-411.

Houpt, T.A. and Berlin, R. 1999. Rapid, labile, and protein synthesis-independent short-term memory in conditioned taste aversion. Learn. Mem. 6: 37-46.

Huh, G.S., Boulanger, L.M., Du, H., Riquelme, P.A., Brotz, T.M., and Shatz, C.J. 2000. Functional requirement for class I MHC in CNS development and plasticity. Science 290: 2155-2159.

Idriss, H.T., Al-Assar, O., and Wilson, S.H. 2002. DNA polymerase $\beta$. Int. J. Biochem. Cell Biol. 34: 321-324.

Igaz, L.M., Vianna, M.R., Medina, J.H., and Izquierdo, I. 2002. Two time periods of hippocampal mRNA synthesis are required for memory consolidation of fear-motivated learning. J. Neurosci. 22: 6781-6789. 
DNA Recombination/Repair and Long-Term Memory

Josselyn, S., Kida, S., Peña de Ortiz, S., and Silva, A.J. 2002. CREB, plasticity, and memory. In Handbook of chemical neuroanatomy: Immediate early genes and inducible transcription factors in mapping of the central nervous system function and dysfunction. (eds. L. Kaczmarek and H.A. Robertson), pp. 329-361. Elsevier Science B.V., Amsterdam, The Netherlands.

Kempermann, G., Kuhn, H.G., and Gage, F.H. 1998. Experience-induced neurogenesis in the senescent dentate gyrus. J. Neurosci. 18: $3206-3212$.

Lamprecht, R., Hazvi, S., and Dudai, Y. 1997. cAMP response element-binding protein in the amygdala is required for long- but not short-term conditioned taste aversion memory. J. Neurosci. 17: 8443-8450.

Lee, Y., Barnes, D.E., Lindahl, T., and McKinnon, P.J. 2000. Defective neurogenesis resulting from DNA ligase IV deficiency requires Atm. Genes \& Dev. 14: 2576-2580.

Manahan-Vaughan, D., Kulla, A., and Frey, J.U. 2000. Requirement of translation but not transcription for the maintenance of long-term depression in the CAI region of freely moving rats. J. Neurosci. 20: 8572-8576.

Naghdi, N., Majlessi, N., and Bozorgmehr, T. 2003. The effects of anisomycin (a protein synthesis inhibitor) on spatial learning and memory in CA1 region of rats hippocampus. Behav. Brain Res. 139: 69-73.

Naor, C. and Dudai, Y. 1996. Transient impairment of cholinergic function in the rat insular cortex disrupts the encoding of taste in conditioned taste aversion. Behav. Brain Res. 79: 61-67.

Nilsson, M., Perfilieva, E., Johansson, U., Orwar, O., and Eriksson, P.S. 1999. Enriched environment increases neurogenesis in the adult rat dentate gyrus and improves spatial memory. J. Neurobiol. 39: $569-578$.

Ohno, Y., Spriggs, D., Matsukage, A., Ohno, T., and Kufe, D. 1988. Effects of 1- $\beta$-D-arabinofuranosylcytosine incorporation on elongation of specific DNA sequences by DNA polymerase $\beta$. Cancer Res. 48: 1494-1498.
Paxinos, G. and Watson, C. 1998. The rat brain in stereotaxic coordinates Academic Press, Sydney, Australia.

Peña de Ortiz, S. and Arshavsky, Y.I. 2001. DNA recombination as a possible mechanism in declarative memory: A hypothesis. $J$. Neurosci. Res. 63: 72-81.

Peña de Ortiz, S., Colón, M., Carrasquillo, Y., Ren, K., Padilla, B., Silva, R., and Arshavsky, Y.I. 2003. Experience-dependent expression of the gene encoding terminal deoxynucleotidyl transferase in the mouse brain. Neuroreport. 14: 1141-1144.

Ren, K. and Peña de Ortiz, S. 2002. Nonhomologous DNA end joining in the mature rat brain. J. Neurochem. 80: 949-959.

Shivji, M.K., Podust, V.N., Hubscher, U., and Wood, R.D. 1995. Nucleotide excision repair DNA synthesis by DNA polymerase $\epsilon$ in the presence of PCNA, RFC, and RPA. Biochemistry 34: 5011-5017.

Shors, T.J., Miesegaes, G., Beylin, A., Zhao, M., Rydel, T., and Gould, E. 2001. Neurogenesis in the adult is involved in the formation of trace memories. Nature 410: $372-376$.

Silva, A.J. 2003. Molecular and cellular cognitive studies of the role of synaptic plasticity in memory. J. Neurobiol. 54: 224-237.

Sugo, N., Aratani, Y., Nagashima, Y., Kubota, Y., and Koyama, H. 2000 Neonatal lethality with abnormal neurogenesis in mice deficient in DNA polymerase $\beta$. EMBO J. 19: 1397-1404.

van Praag, H., Kempermann, G., and Gage, F.H. 2000. Neural consequences of environmental enrichment. Nat. Rev. Neurosci. 1: $191-198$.

Wang, L.M., White, J.C., and Capizzi, R.L. 1990. The effect of ara-C-induced inhibition of DNA synthesis on its cellular pharmacology. Cancer Chemother. Pharmacol. 25: 418-424.

Yin, J.C. and Tully, T. 1996. CREB and the formation of long-term memory. Curr. Opin. Neurobiol. 6: 264-268.

Zittoun, J., Marquet, J., and David, J.C. 1991. Mechanism of inhibition of DNA ligase in Ara-C treated cells. Leuk. Res. 15: 157-164.

Received May 9, 2003; accepted in revised form September 3, 2003. 


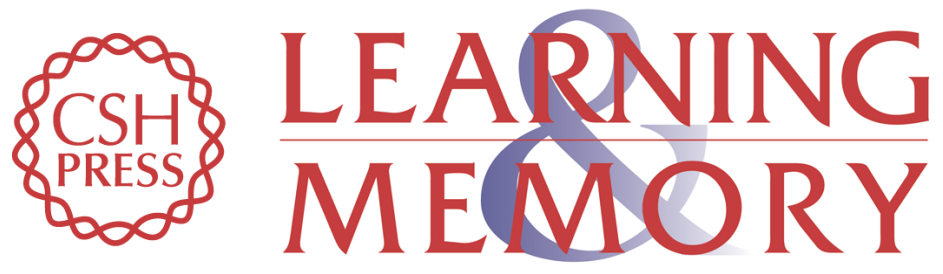

\section{The Antimetabolite ara-CTP Blocks Long-Term Memory of Conditioned Taste Aversion}

Jianpeng Wang, Keqin Ren, Javier Pérez, et al.

Learn. Mem. 2003, 10:

Access the most recent version at doi:10.1101/lm.63003

References This article cites 51 articles, 14 of which can be accessed free at:

http://learnmem.cshlp.org/content/10/6/503.full.html\#ref-list-1

License

Email Alerting Receive free email alerts when new articles cite this article - sign up in the box at the Service top right corner of the article or click here. 